\section{Are rehabilitation services for patients in UK eye clinics adequate? A survey of eye care professionals}

H Gillespie-Gallery, ML Conway and A Subramanian
Department of Optometry and Visual Science, City University London, London, UK

Correspondence: A Subramanian, Department of Optometry and Visual Science, City University London, Northampton Square, London EC1V OHB, UK Tel: + 44 (0)20 70404326 ; Fax: + 44 (0)20 70408494 E-mail: Ahalya.Subramanian.1 @city.ac.uk

Received: 20 May 2011 Accepted in revised form: 9 May 2012

Published online: 20 July 2012

Previous presentations of this work: Gillespie-Gallery $H$, Subramanian A, Conway M. Evaluating the impact of Eye Care Liaison Officers. Presented at the Vision UK Annual Meeting, Birmingham, UK, 2010; GillespieGallery H, Conway M, Subramanian A. Services for visually impaired people in the UK: Is there room for improvement? Presented at the Annual Meeting of the Association for Research in Vision and Ophthalmology, Fort Lauderdale, FL, USA, 2010; Gillespie-Gallery H, Conway M, Subramanian A The opinions of eye care professionals on patient related, low vision services in the UK. Presented at the College of Optometrists Research Symposium, York, UK, 2010.

\begin{abstract}
Purpose The purpose of this study is to determine whether specific services such as emotional and family support are currently available in the United Kingdom for people with visual impairment.

Methods A validated online survey was created and distributed to clinical staff in eye clinics (for example, ophthalmologists and optometrists) and rehabilitation staff (for example, social and rehabilitation workers) in the community, who worked with people with visual impairment. A total of 67 clinical and 42 rehabilitation staff completed the entire survey online.

Results Only $67 \%$ of the respondents
\end{abstract} claimed their clinics provide emotional support and $44 \%$ of respondent's clinics provided family support. Clinical and rehabilitation staff have differences in opinion over what constitutes an essential service for a visually impaired patient. Rehabilitation staff considered emotional support and referral to social services as essential more often than clinical staff $(P<0.05)$. There is some confusion over the type of personnel who provides each type of service, with some services showing substantial repetition.

Conclusion In the clinics sampled, there appears to be an underprovision of emotional support (attentive listening plus constructive suggestions) and family support (emotional support and advice for family members) for visually impaired patients in the United Kingdom. There also seems to be some discrepancy in services that eye care professionals feel are available and previous reports by visually impaired patients of the service they receive. There is a need to develop standardised pathways across the United Kingdom, to solve some of these issues. Eye (2012) 26, 1302-1309; doi:10.1038/eye.2012.141; published online 20 July 2012

Keywords: rehabilitation; visually impaired persons; public health

\section{Introduction}

Visual impairment has wide-ranging consequences for many aspects of an individual's life, from education ${ }^{1}$ to reduced independence. ${ }^{2}$ It can also mean that other aspects of health suffer because the individual is more likely to have falls ${ }^{3}$ and may be prone to depression. ${ }^{4}$

Many conditions resulting in visual impairment cannot be cured or alleviated, resulting in rehabilitation services being the main source of care. Rehabilitation aims to reduce disability ${ }^{5}$ so that the impact of the impairment is minimised. Rehabilitation services can include the examination of vision, emotional support, training with low-vision aids and orientation, and mobility training. In the United Kingdom, the majority of low-vision examinations are provided in the hospital. Besides having a low-vision examination, patients also require other forms of help, such as emotional and family support. This tends to be provided in the community by social services, although in some hospitals, this may be provided by the eye care liaison officer. A typical patient journey would include a visit to a low-vision clinic, followed by referral to social services.

Culham $e t a l^{6}$ suggested there was an underprovision in the number of low-vision consultations offered in hospitals per year, 
and furthermore, there is evidence to suggest that many eligible patients do not receive any support at all. For example, Douglas et $a l^{1}$ found that $17 \%$ of those registered within the previous 8 years received no services.

A specific service that may be necessary for people with visual impairments is emotional support and counselling, particularly in the initial stages of the disease; yet, these needs are often overlooked. Research has shown that after an appointment at an eye clinic, 70\% of the patients wanted to talk to someone about their concerns, but only $19 \%$ were given the opportunity to do so. ${ }^{7}$ Douglas et $a l^{1}$ found that registered individuals who were dissatisfied with the services they had received often mention they would have appreciated emotional support and counselling.

In addition, the services that are available and the way they are accessed can vary considerably according to previous reports. ${ }^{8}$ The aim of the current study was therefore to investigate if there is currently an underprovision of specific services for visually impaired individuals in eye clinics and in the community in the United Kingdom. These aims were investigated by creating a survey for professionals who worked in the area of visual impairment in the United Kingdom.

\section{Materials and methods}

A survey was designed to evaluate whether specific services such as emotional and family support were currently available in eye clinics for visually impaired people in the United Kingdom.

The questions for the pilot survey were identified from discussions with other researchers in low vision. The initial version of the survey was piloted with 12 eye care professionals who worked either in a hospital or in the community. The questionnaire was checked for face validity by two experienced eye care professionals, and questions amended based on comments received from them as well as from the professionals who participated in the pilot study. The amendments were minor changes in the wording of a few questions to make them clearer and more relevant to the service users that the respondents worked with. The questions were found to have a good degree of test-retest reliability when the questionnaire was re-administered (observed $\kappa=0.75$ ) approximately 3-5 weeks later (mean $=3.6$ weeks).

The final version of the questionnaire was completed anonymously by two groups of professionals: the clinical staff (examples include optometrists) and the rehabilitation staff (examples include rehabilitation officers). Various professional bodies and groups agreed to send a link to the questionnaire to their members via email (see Acknowledgements). A list of the questions asked can be found in Table 1 . The questionnaire administered to the two groups of professionals was slightly different to account for the different roles that these individuals undertake. All questions were optional, apart from filtering questions. Filtering questions were used, so that only respondents whose role required them to be aware of low-vision services in relevant clinic(s)/ hospital(s) answered question 1. For example, a rehabilitation officer, who answered 'yes' to the filtering question 'Does your position require you to be aware of low-vision services at hospitals or clinics?' would go on to answer question 1. Another filtering question made sure that only respondents whose role required them to be aware of the roles of staff in the clinic/hospital (if a clinical staff) or the community (if a non-clinical staff) answered question 3. Respondents selected from a list, the services available and/or the personnel responsible, depending on the question. Respondents were also given the opportunity to report additional services.

All participants completed the survey online, using the online tool survey monkey. ${ }^{9}$ Statistical differences were tested for using $\chi^{2}$-analysis and Fisher's exact test in SPSS, version 17.0 (SPSS Inc., Chicago, IL, USA).

\section{Statement of ethics}

We certify that all applicable institutional and governmental regulations concerning the ethical use of human volunteers were followed during this research.

\section{Results}

\section{Profile of participants completing the survey}

A total of 67 clinical and 42 rehabilitation staff completed the entire survey. Of the 67 clinical staff who completed the survey, there were 9 ophthalmologists, 13 optometrists, 21 orthoptists, 19 dispensing opticians, 2 nurses, and 3 other health care professionals. In all, $65.7 \%$ of clinical staff worked in hospitals, $23.9 \%$ in private practices, and $10.4 \%$ in other settings (including charities, schools, and patients' homes). Of the 42 rehabilitation staff who completed the survey, there were 36 rehabilitation workers, 4 social or support workers, and 2 managers. In all, $81.0 \%$ carried out most of their work from the patients' homes, $7.1 \%$ in hospitals, and $33.3 \%$ mentioned that they also carried out work in other places, including schools, low-vision centres, nursing homes, and social services offices.

\section{Response rate}

There are no recent estimates of how many practitioners provide low-vision services in the United Kingdom or 
Table 1 List of questions used in the final version of the survey

\begin{tabular}{l} 
Question \\
\hline $1 \quad$ Which of the following services are available in your \\
PCT/hospital to visually impaired people with sight loss, \\
who are eligible for certification as sight-impaired or severel \\
sight-impaired? \\
a Explanation of the cause of the patient's vision loss and \\
prognosis \\
b Explanation of the process of registration \\
c Explanation about the use of low-vision aids \\
$\mathrm{d}$ Training in the use of low-vision aids \\
$\mathrm{e}$ Explanation about the use of non-optical aids. Eg, lighting \\
$\mathrm{f}$ Referring to social services \\
$\mathrm{g}$ Family support \\
$\mathrm{h}$ Emotional support (excluding counselling) \\
$\mathrm{i}$ Sign-posting to other sources of help
\end{tabular}

2 Which of the following services do you feel are essential to the care of visually impaired people with sight loss, who are eligible for certification as sight-impaired or severely sight-impaired?

a Explanation of the cause of the patient's vision loss and prognosis

b Explanation of the process of registration

c Explanation about the use of low-vision aids

d Training in the use of low-vision aids

e Explanation about the use of non-optical aids. Eg, lighting

f Referring to social services

g Family support

h Emotional support (excluding counselling)

i Sign-posting to other sources of help

3 Clinical staff were asked the question: Which members of staff in your PCT/local hospital provide the following patient-related services? If these services overlap between personnel, you may select multiple personnel

Rehabilitation staff were asked the question:

Which members of staff in your local authority provide the following patient-related services? If these services overlap between personnel, you may select multiple personnel

a Explanation of the cause of the patient's vision loss and prognosis

$\mathrm{b}$ Explanation of the process of registration

c Explanation about the use of low-vision aids

d Training in the use of low-vision aids

e Explanation about the use of non-optical aids. Eg, lighting

f Referring to social services

g Family support

h Emotional support (excluding counselling)

i Sign-posting to other sources of help
What professional answered the question?

Clinical and rehabilitation staff who responded 'yes' to the filtering question 'Does your position require you to be aware of low-vision services at hospitals or clinics?'

All clinical and rehabilitation staff

Clinical staff who answered yes to the filtering question, 'Does your position require you to be aware of the duties/roles of different members of clinical staff at your hospital/clinic?'

Rehabilitation staff who answered yes to the filtering question, 'Does your position require you to be aware of the duties/roles of different members of staff in your local authority who are relevant to patients who are sight-impaired?' are required to know about the availability of such services as part of their job. However, a study published by Ryan and Culham ${ }^{8}$ in 1999 found that of the 1945 respondents surveyed who might potentially provide low-vision services, $41 \%$ (803) did not offer a service, $26 \%$ (497) only sold magnifying aids (without assessment or professional input), and 33\% (638) provided low-vision services that included the provision of low-vision aids, training, and or counselling. Excluding the 803 who did not offer low-vision services, our response rate would range from 9.6 (including those that only provided magnifying aids) to $17 \%$ (excluding those that only provided magnifying aids). Our true response rate probably lies somewhere between these figures. However, this estimate should be considered with caution because low-vision service provision has increased since 1999, particularly with the onset of the Welsh Low-Vision initiative, and also, not all low-vision 
Table 2 Available services for individuals who are visually impaired, and how essential these services are according to clinical and rehabilitation staff

\begin{tabular}{|c|c|c|c|c|c|c|}
\hline \multirow[t]{2}{*}{ Service } & \multicolumn{2}{|c|}{ Clinical staff } & \multicolumn{2}{|c|}{ Rehabilitation staff } & \multicolumn{2}{|c|}{$\begin{array}{l}\text { Average of clinical and } \\
\text { rehabilitation staff }\end{array}$} \\
\hline & $\begin{array}{l}\text { Percentage of } \\
\text { respondents who } \\
\text { felt the service was } \\
\text { available }(\mathrm{n}=72)\end{array}$ & $\begin{array}{l}\text { Percentage of } \\
\text { respondents who } \\
\text { felt the service was } \\
\text { essential }(\mathrm{n}=81)\end{array}$ & $\begin{array}{l}\text { Percentage of } \\
\text { respondents who } \\
\text { felt the service was } \\
\text { available }(\mathrm{n}=54)\end{array}$ & $\begin{array}{l}\text { Percentage of } \\
\text { respondents who } \\
\text { felt the service was } \\
\text { essential }(\mathrm{n}=53)\end{array}$ & $\begin{array}{l}\text { Percentage of } \\
\text { respondents who } \\
\text { felt the service was } \\
\text { available }(\mathrm{n}=126)\end{array}$ & $\begin{array}{l}\text { Percentage of } \\
\text { respondents who } \\
\text { felt the service was } \\
\text { essential }(\mathrm{n}=134)\end{array}$ \\
\hline $\begin{array}{l}\text { Explanation of the } \\
\text { cause of the } \\
\text { patient's vision } \\
\text { loss and prognosis }\end{array}$ & 93 & 99 & 81 & 100 & 88 & 99 \\
\hline $\begin{array}{l}\text { Explanation of the } \\
\text { process of } \\
\text { registration }\end{array}$ & 93 & 96 & 89 & 100 & 91 & 98 \\
\hline $\begin{array}{l}\text { Explanation about } \\
\text { the use of } \\
\text { low-vision aids }\end{array}$ & 96 & 97 & 76 & 96 & 87 & 97 \\
\hline $\begin{array}{l}\text { Training in the use } \\
\text { of low-vision aids }\end{array}$ & 94 & 99 & 59 & 94 & 79 & 97 \\
\hline $\begin{array}{l}\text { Explanation about } \\
\text { the use of non- } \\
\text { optical aids }\end{array}$ & 90 & 100 & 56 & 94 & 75 & 98 \\
\hline $\begin{array}{l}\text { Referring to social } \\
\text { services }\end{array}$ & 93 & 88 & 96 & 100 & 94 & 93 \\
\hline Family support & 50 & 83 & 35 & 87 & 44 & 84 \\
\hline $\begin{array}{l}\text { Emotional support } \\
\text { (excluding } \\
\text { counselling) }\end{array}$ & 67 & 86 & 67 & 98 & 67 & 91 \\
\hline $\begin{array}{l}\text { Sign-posting to } \\
\text { other sources of } \\
\text { help }\end{array}$ & 89 & 91 & 76 & 92 & 83 & 92 \\
\hline
\end{tabular}

service providers may have been indentified by Ryan and Culham's study.

Of the 76 respondents specifying their location, $73.7 \%$ of respondents worked in England, $11.8 \%$ in Northern Ireland, $7.9 \%$ in Wales, and $6.6 \%$ in Scotland. This distribution is broadly similar to the distribution of the 143 ophthalmology clinics in the United Kingdom (personal correspondence with the Royal College of Ophthalmologists). The majority of these clinics ( $n=120$, $83.9 \%)$ are located in England, and smaller numbers are located in Scotland $(n=13,9.1 \%)$, Wales $(n=8,5.6 \%)$, and Northern Ireland $(n=2,1.4 \%)$. Therefore, in the current survey, England was somewhat underrepresented and Northern Ireland somewhat overrepresented.

What services are available in eye clinics for individuals with sight loss, who are eligible for registration?

Clinical and rehabilitation staff were asked about the services available (for example, explanation of the cause of vision loss) at the hospital they worked at most or at hospitals in their local authority, respectively. They were also asked if they felt the service was essential or not, regardless of whether the service was currently available. The results are shown in Table 2. To determine if there were statistical differences in the reported availability and services deemed essential, a $\chi^{2}$-analysis was performed. Only participants who answered both questions were included $(n=69$ clinical staff and $n=52$ rehabilitation staff).

\section{Clinical staff}

The results suggest that within the United Kingdom, there is a good supply of the following services: explanation of cause of the patients' vision loss and prognosis, explanation of the registration process, explanation and training about the use of low-vision aids and non-optical aids, referral to social services, and sign-posting to other sources of help, with $89 \%$ 
or more respondents reporting that the service was available within their Trust or Health Board. The only services not widely available included, family (50\%) and emotional support (67\%) (Table 2). No statistical differences were found $(P<0.05)$ between the services deemed to be essential and those available.

\section{Rehabilitation staff}

Findings were slightly different for rehabilitation staff. They reported that in hospitals, services such as family support (35\%) were not as widely available as services such as explanation of the process of registration (89\%; Table 2). Significant differences were found between services deemed to be essential and those available for explanation of low-vision aids, training in low-vision aids, and sign-posting to other services $(P<0.05)$.

Are there differences in opinion between clinical and rehabilitation staff for services thought to be available for visually impaired patients?

The estimates of which services were available in hospitals were compared between clinical and rehabilitation staff. Statistically significant differences were found for explanation of the use of low-vision aids $(P<0.01)$, explanation of the use of non-optical aids $(P<0.001)$, and training in the use of low-vision aids $(P<0.001)$. In all cases, a greater proportion of the clinical staff reported that the particular service was available when compared with the rehabilitation staff.

\section{Are there differences in opinion between clinical and rehabilitation staff for services thought to be essential for visually impaired patients?}

The opinions about the services deemed essential for individuals with visual impairment were compared between clinical and rehabilitation staff. Significant differences in the services deemed essential for individuals with vision loss were found for referring to social services $(P<0.05)$ and emotional support $(P<0.05)$. Rehabilitation staff were more likely to feel that emotional support and referring to social services was essential.

\section{Who provides patient-related services in the hospital/ PCT?}

The clinical staff were asked who was responsible for providing patient-related services in their hospital/PCT for visually impaired patients, and the rehabilitation staff were asked about who provides these services in the local authority at large (including in hospitals; Tables 3 and 4). If more than one member of the staff provided a service, these were listed in the 'multiple personnel' column. Interestingly, only 29 clinical and 16 rehabilitation staff answered this question.

\section{Results from clinical staff}

For most services in the clinic, no individual is responsible for delivering a service, because it was provided by multiple personnel (these services are explanation of the cause of vision loss, explanation of the process of registration, explanation about the use of non-optical aids, referring to social services, and sign-posting to other sources of help). There were also gaps in the care provided, particularly for family and emotional support because often no one provided this service (Table 3 ).

\section{Results from rehabilitation staff}

The results show that in the local authority at large, the rehabilitation staff are the main provider of training in low-vision aids; however, multiple personnel frequently provided all other services. All the services

Table 3 Services provided by different eye care professionals: findings from the clinical staff survey $(n=29)$

\begin{tabular}{|c|c|c|c|c|c|c|c|c|}
\hline Service & Ophthalmologist & Optometrist & Orthoptist & Nurse & $\begin{array}{c}\text { Other } \\
\text { personnel }\end{array}$ & $\begin{array}{l}\text { Not } \\
\text { sure }\end{array}$ & $\begin{array}{l}\text { Multiple } \\
\text { personnel }\end{array}$ & No one \\
\hline Explanation of the cause of vision loss & 37.9 & 0.0 & 3.4 & 0.0 & 6.9 & 3.4 & 48.3 & 0.0 \\
\hline Explanation of the process of registration & 27.6 & 3.4 & 3.4 & 6.9 & 20.7 & 0.0 & 34.5 & 3.4 \\
\hline Explanation about the use of low-vision aids & 0.0 & 17.2 & 34.5 & 0.0 & 0.0 & 24.1 & 17.2 & 6.9 \\
\hline Training in the use of low-vision aids & 0.0 & 24.1 & 34.5 & 0.0 & 20.7 & 3.4 & 10.3 & 6.9 \\
\hline Explanation about the use of non-optical aids & 0.0 & 13.8 & 20.7 & 3.4 & 13.8 & 3.4 & 37.9 & 6.9 \\
\hline Referring to social services & 13.8 & 3.4 & 3.4 & 3.4 & 20.7 & 6.9 & 44.8 & 3.4 \\
\hline Family support & 0.0 & 0.0 & 0.0 & 0.0 & 24.1 & 17.2 & 10.3 & 48.3 \\
\hline Emotional support & 0.0 & 3.4 & 6.9 & 6.9 & 13.8 & 20.7 & 13.8 & 34.5 \\
\hline Sign-posting to other sources of help & 0.0 & 3.4 & 10.3 & 3.4 & 20.7 & 3.4 & 44.8 & 13.8 \\
\hline
\end{tabular}

Results in 'bold' show the most frequent response. 
Table 4 Services provided by different eye care professionals: findings from the rehabilitation staff survey $(n=16)$

\begin{tabular}{|c|c|c|c|c|c|c|c|c|c|}
\hline Service & $\begin{array}{c}\text { Hospital } \\
\text { Staff }\end{array}$ & $\begin{array}{c}\text { Rehab } \\
\text { workers }\end{array}$ & $\begin{array}{l}\text { Low-vision } \\
\text { therapists }\end{array}$ & $\begin{array}{c}\text { Occupational } \\
\text { therapists }\end{array}$ & $\begin{array}{c}\text { Social } \\
\text { workers }\end{array}$ & Other & $\begin{array}{l}\text { Not } \\
\text { sure }\end{array}$ & $\begin{array}{l}\text { Multiple } \\
\text { personnel }\end{array}$ & $\begin{array}{l}\text { No } \\
\text { one }\end{array}$ \\
\hline Explanation of the cause of vision loss & 12.5 & 25.0 & 0.0 & 0.0 & 0.0 & 0.0 & 0.0 & 62.5 & 0.0 \\
\hline Explanation of process of registration & 6.3 & 31.3 & 0.0 & 0.0 & 0.0 & 0.0 & 0.0 & 62.5 & 0.0 \\
\hline Explanation about the use of low-vision aids & 6.3 & 25.0 & 0.0 & 0.0 & 0.0 & 0.0 & 0.0 & 68.8 & 0.0 \\
\hline Training in the use of low-vision aids & 6.3 & 56.3 & 0.0 & 0.0 & 0.0 & 0.0 & 0.0 & 37.5 & 0.0 \\
\hline Explanation about the use of non-optical aids & 0.0 & 43.8 & 0.0 & 0.0 & 0.0 & 0.0 & 0.0 & 56.3 & 0.0 \\
\hline Referring to social services & 18.8 & 6.3 & 0.0 & 0.0 & 0.0 & 0.0 & 6.3 & 68.8 & 0.0 \\
\hline Family support & 0.0 & 18.8 & 0.0 & 0.0 & 0.0 & 6.3 & 6.3 & 68.8 & 0.0 \\
\hline Emotional support & 0.0 & 31.3 & 0.0 & 0.0 & 0.0 & 6.3 & 12.5 & 50.0 & 0.0 \\
\hline Sign-posting to other sources of help & 6.3 & 25.0 & 0.0 & 0.0 & 0.0 & 0.0 & 0.0 & 68.8 & 0.0 \\
\hline
\end{tabular}

Results in 'bold' show the most frequent response.

surveyed appear to be provided by personnel in the community (Table 4).

\section{Discussion}

\section{Services for people with visual impairment}

Overall, it would appear, from an eye care professional's point of view, that a majority of services such as explanation of the cause of vision loss are available to visually impaired patients, both in the hospital and in the community. In the current survey, eye care professionals in eye clinics felt that explanation about the use of low-vision aids was available to at least $96 \%$ of patients attending the hospital. However, the story is different when looked at from the patients' perspective; only $45 \%$ of patients surveyed by Douglas et al ${ }^{10}$ felt that they had been provided with information about low-vision aids. Similar findings were found for other services such as social care routes.

There are two reasons for these findings. First, it could be that these services are provided and available, but they are not known to or being accessed by patients. Second, the responses from eye care professionals and/or patients could be inaccurate because a survey gathers information subjectively. For example, we found that up to $24 \%$ of clinical staff were unsure about who provided some services, and they may have less knowledge on what services are available in the hospital. The rehabilitation staff may have underreported the availability of some services in eye clinics when compared with the clinical staff because they have less knowledge on what services are available. In addition, as these services are not always commonplace, the respondents may not have fully understood what they are, and thus misreported them. The experiences of patients are often collected retrospectively, which may make them unreliable. For example, Douglas et al ${ }^{1}$ investigated which services patients received in the clinic when they were first registered, and some patients were registered 8 years previously. Either way, there are discrepancies between services that the eye care professionals feel are provided and services that the patients feel they receive. To accurately assess what services are available, a clinical audit of services available and whether eligible patients are receiving them should be carried out. This will help determine whether services are being inaccurately reported, or patients are not accessing the services appropriately. If patients are not accessing services properly, it would support the development of referral pathways for services in social and clinical care.

Although eye care professionals feel that a majority of services are available, some services, family (50\%) and emotional support $(67 \%)$, are less likely to be available in eye clinics and there are often no staff to provide it. These results suggest that there is an underprovision of some services in eye clinics at the point of diagnosis. Previous research has suggested a need for family and emotional support because patients were leaving eye clinics feeling depressed and unsupported. ${ }^{7}$ Norwell and Hiles ${ }^{11}$ suggested that patients were often not given information about the help available. NICE guidelines suggest that health care professionals should ask screening questions for depression to those with 'significant physicalillnesses-causing disability' to determine whether referral would be appropriate. ${ }^{12}$ Our results show that, sign-posting to other services, and family and emotional support is not entirely absent; it may still not be meeting the patients' needs.

There were statistically significant differences in the opinion between the clinical and rehabilitation staff on which services considered essential for visually impaired people. Rehabilitation staff were more likely to consider emotional support and referring to social services as essential. One interpretation is that staff only understand specific types of needs, that is, the rehabilitation staff may have a greater understanding of the social needs of the patient because they focus on the disability rather 
than the impairment. ${ }^{13}$ The LOVSME Project ${ }^{14,15}$ supports this idea because they found that of referrals to social services, only $15 \%$ were based on need when registration criteria are not met, suggesting that clinical staff tend to refer individuals for further help only when individuals meet the criteria for registration. Consequently, patients may not be referred to the services providing emotional support by clinical staff, and these services may not be provided in hospitals. It is particularly important that clinicians are sensitive to the emotional needs of patients with vision loss, because depression in this group is often missed by GPs. ${ }^{16}$

Interestingly, only $43 \%$ of clinical and $38 \%$ of rehabilitation staff responded to the question regarding which personnel provided services for visually impaired individuals. This could have been because we used a filtering question, so only those who were required to be aware of the roles of other staff answered this question. One could argue that if staff were unaware of which personnel provided a service, they may not have understood the service itself properly. We believe that this finding actually highlights a gap in the respondent's knowledge of the roles of other staff rather than a lack of knowledge about the service provision because of the filtering question. Indeed for many eye care professionals, it may not be important to know which personnel provides the service, but simply to know which department provides the service so that appropriate referrals can be made. It has also been found that people are more likely to answer a survey if they feel that the survey is important and interesting (salience). ${ }^{17}$ The conclusion would therefore be that only professionals who were interested and aware of the services are likely to have participated.

When investigating who provides services in eye clinics and the community, we found that multiple personnel were responsible for the vast majority of services. For some services, such as explaining the cause of sight loss, it is beneficial that any personnel whom an individual has contact with can provide this explanation. However, for other services, having multiple staff providing the same service is not advantageous. For example, if an individual service is required by a patient, such as information about local societies, a patient would not know who to approach, and eye care professionals may be unsure where to refer them. In addition, the work with patients could be duplicated, which would waste valuable resources. A previous report from 1999 found that there was considerable variation in the extent and nature of collaboration and co-ordination between services. ${ }^{8}$ Again, providing standardised referral pathways would make it clear who was meant to provide each service. Interestingly, in hospitals, orthoptists were reported as the main provider for two of the nine services (explanation and training in the use of low-vision aids) and rehabilitation workers were the main provider in the community of one out of the nine services (training in low-vision aids). Although this may be the case, it may also reflect the fact that orthoptists were the largest group of professional completing the survey for clinical staff, and rehabilitation workers were the largest group completing the survey of those who worked in the community.

We would like to acknowledge the shortcomings of the survey. Because of the recruitment method (asking professional bodies to send a link to the survey to their members), we are unsure how many people received the invitation, and therefore cannot calculate the response rate. In addition, it is unclear what proportion of lowvision services were included in the survey, but we estimate that this was likely to have been between 9.6 and $17 \%$ based on previous estimates from 1999.8 However, the distribution of the study population across the United Kingdom seems to broadly reflect the distribution of eye clinics. Another limitation of the survey is that it only pertains to rehabilitation services that can usefully be provided in the clinic (for example, providing mobility training would be more useful in the patients' local area than in an eye clinic), and these are not necessarily all the services that would be required by an individual with low-vision loss. For example, most of the services discussed in the survey are provided by eye care liaison officers ${ }^{18}$ who work in a limited number of clinics in the United Kingdom. Respondents were given the opportunity to comment about any other services provided, but very few were mentioned so the results were not included. One oversight, however, was that the participants were not asked about the provision of lowvision aids in the survey, only training, and explanation of their use.

In conclusion, there is a lack of emotional and family support in many eye clinics in the United Kingdom. To help improve services provided to visually impaired people, an 'Assessment Framework' was designed by the RNIB's LOVESME group $^{19}$ and suggested ways to identify gaps in care, and provide for the social and psychological needs of patients. In addition, referral pathways need to be developed for the patient journey through clinical and social care to ensure that both patients and health practitioners know what services exist, to make it clear who provides individual services, and to encourage clinicians to make appropriate referrals. Referral pathways have been developed by a range of organisations, including the Welsh Low-Vision Service, Map of Medicine, ${ }^{20}$ and some eye clinics. ${ }^{21}$ However, there are no standardised referral pathways through both social and clinical care. 
Summary

\section{What was known before}

- Visual impairment has wide-ranging consequences on many aspects of an individual's life, and many conditions resulting in visual impairment cannot be cured or alleviated, resulting in rehabilitation services being the main source of care.

- Besides having a low-vision examination, patients with visual impairment also require other forms of help, such as emotional and family support.

- However, there may be an underprovision of these services in the United Kingdom.

What this study adds

- There is an underprovision of emotional and family support in eye clinics in the United Kingdom according to eye care professionals in hospitals and the community.

- Clinical staff reported higher availability of some services than was suggested by patients in the previous research.

- This suggests either the responses are inaccurate, or that patients are not accessing services that are available.

- Clinical and rehabilitation staff differ in what services they feel are essential to patients.

\section{Conflict of interest}

The authors declare no conflict of interest.

\section{Acknowledgements}

We would like to thank Sally Kaye and Joanna Hook for assisting with the development of the survey, and the participants who took part in the pilot study. We would also like to thank everyone who completed the survey from the following professional bodies and groups: The College of Optometrists, Association of British Dispensing Opticians, British and Irish Orthoptic Society, Royal College of Ophthalmologists, London Rehabilitation Workers Forum, Southern Rehab Forum, Yorkshire Regional Rehabilitation Workers Group, Midlands Rehabilitation Workers Group, North West Special Interest Group, Wales Rehab Forum, Fife Society for the Blind, Rehabilitation workers in Northern Ireland. This project was funded by the RNIB.

\section{References}

1 Douglas G, Pavey S, Corcoran C. Access to Information, Services and Support for People with Visual Impairment. Vision 2020: UK, 2008

2 Marx MS, Werner P. The eye disorders of residents of a nursing home. I Visual Impair Blind 1994; 88: 462-468.
3 Vu HTV, Keeffe JE, McCarty CA, Taylor HR. Impact of unilateral and bilateral vision loss on quality of life. Brit J Ophthalmol 2005; 89: 360-363.

4 Rees G, Saw CL, Lamoureux EL, Keeffe JE. Self-management programs for adults with low vision: needs and challenges. Patient Educ Couns 2007; 69: 39-46.

5 Massof RW, Hsu CT, Baker FH, Barnett GD, Park WL Deremeik JT et al. Visual disability variables. II: the difficulty of tasks for a sample of low-vision patients. Arch Phys Med Rehabil 2005; 86: 954-967.

6 Culham LE, Ryan B, Jackson AJ, Hill AR, Jones B, Miles C et al. Low vision services for vision rehabilitation in the United Kingdom. Brit J Ophthalmol 2002; 86: 743-747.

7 McBride S. Patients with severe sight loss: emotional support and counselling. Optometry Today 2005; 36-37.

8 Ryan B, Culham L. Fragmented Vision: Survey of Low Vision Services in the UK. RNIB: London, 1999.

9 Survey Monkey. http://www.surveymonkey.com/ (accessed 25 March 2011).

10 Douglas G, Pavey S, Corcoran C, Eperjesi F. Individual's recollections of their experiences in eye clinics and understanding of their eye condition: results from a survey of visually impaired people in Britain. Ophthal Physl Opt 2010; 30: 748-757.

11 Norwell C, Hiles C. Why every hospital should have an eye clinic liaison officer. Int Congr Ser 2005; 1282: 226-229.

12 National Institute for Clinical Excellence. Depression: Management of Depression in Primary and Secondary Care. http://www.nice.org.uk/nicemedia/live/10957/29592/ 29592.pdf (accessed 22 August 2011).

13 World Health Organisation. International Classification of Functioning, Disability and Health. http:/ /www.who.int/ classifications/icf/en/ (accessed 2 June 2010).

14 Binns AM, Bunce C, Dickinson C, Harper R, TudorEdwards $\mathrm{R}$, Woodhouse $\mathrm{M}$ et al. How effective is low vision service provision? A systematic review. Surv Ophthalmol 2012; 57: 34-65.

15 Dickinson C, Linck P, Tudor-Edwards R, Binns A, Bunce C, Harper $\mathrm{R}$ et al. A profile of low vision services in England: the Low Vision Service Model Evaluation (LOVSME) project. Eye 2011; 25: 829-831.

16 Crawford MJ, Prince M, Menezes P, Mann AH. The recognition and treatment of depression in older people in primary care. Int J Geriatr Psychiatry 1998; 13: 172-176.

17 Sheehan KB, McMillan SJ. Response variation in e-mail surveys: an exploration. J Advert Res 1999; 39: 45-54.

18 Royal National Institute of Blind People. Eye Clinic Liaison Officers (ECLOs). http:/ / www.rnib.org.uk/eyehealth/who/ eclo/Pages/about_eclos.aspx (accessed 2 April 2012).

19 Low Vision Service Model Evaluation (LOVSME) collaboration. Low Vision Services Assessment Framework: A Tool for Service Providers. http://www.rnib.org.uk/ aboutus/Research/reports/2011/LOVESME_Assessment Framework.pdf (accessed 22 August 2011).

20 Map of Medicine. http://www.mapofmedicine.com/ (accessed 24 March 2011).

21 Douglas G, Spurgeon P, Pavey S. An exploratory study of the impact of non-medical eye clinic support services (ECSS) in hospital eye clinics. Int Congr Ser 2005; 1282: 105-108. 